\title{
CINÉTICA DE SECAGEM DA FRUTA PHYSALIS POR IRRADIAÇÃO INFRAVERMELHA
}

\author{
R.M. PIGNATA ${ }^{1}$, L.C.C.B. OLIVEIRA ${ }^{1}$ e S.C. DANTAS ${ }^{1}$ \\ ${ }^{1}$ Universidade Federal do Triângulo Mineiro, Departamento de Engenharia Química \\ E-mail para contato: sandra@icte.uftm.edu.br
}

\begin{abstract}
RESUMO - A Physalis é uma fruta originária da Colômbia, a qual possui uma grande quantidade de compostos bioativos e um sabor exótico e singular. Em virtude da sua crescente produção, suas inúmeras propriedades medicinais e principalmente de seus elevados teores de vitaminas e minerais, o presente trabalho buscou analisar a variação dos teores de acidez total titulável, ácido ascórbico e grau brix da fruta in natura e após o processo de secagem a partir do uso de radiação infravermelha. Esse processo proporciona menores custos de transporte e armazenamento além de prolongar a vida útil do alimento, fator esse ocasionado pela redução da atividade enzimática e microbiológica. Os testes de secagem foram realizados nas temperaturas: 60,70 e $80^{\circ} \mathrm{C}$. Pôde-se observar que o modelo de Page é o que melhor descreve a cinética de secagem, apresentando um coeficiente de determinação médio de 0,9992 . Todos os compostos bioativos apresentaram maiores teores após a secagem, e o teor de vitamina $\mathrm{C}$ teve um aumento de quase $40 \%$ no material seco a $60^{\circ} \mathrm{C}$. Os resultados mostraram que a secagem pelo método infravermelho é eficiente na concentração do teor dos compostos bioativos.
\end{abstract}

\section{INTRODUÇÃO}

A fruta physalis é caracterizada como uma baga carnosa arredondada (Puente et al., 2011), típica de regiões de clima temperado e subtropical. O Brasil é o terceiro maior produtor mundial da fruta, onde os principais pontos de cultivo são Rio Grande do Sul e Santa Catarina (Luchese, 2013) Esta fruta apresenta elevadas quantidades de vitaminas A, B1, B2, B3 e C, além de sais minerais como potássio, magnésio, fósforo e ferro além de outros compostos em menor quantidade. (Ramadan e Moersel, 2004; Ramadan, 2011; Puente et al., 2011). Suas inúmeras propriedades medicinais, particularmente associadas ao tratamento quimioterapêutico e prevencional do câncer, juntamente com as características nutracêuticas explicam o crescente interesse na produção da fruta nos últimos anos.

O maior índice de consumo da physalis ocorre na forma in natura, o que eleva o custo de comercialização e transporte devido à alta perecibilidade da fruta. O elevado teor de umidade é um dos fatores que afetam sua qualidade, implicando em perdas qualitativas e quantitativas durante seu período de produção e armazenamento. A remoção da água se apresenta como uma importante alternativa para tal impasse. Existem diversos modos de secagem, sendo o método que faz uso da radiação infravermelha um dos mais utilizados. Gardusi et al. (2013) aponta que o processo faz uso de um equipamento simples, de fácil manuseio e gasto energético, significativamente, menor que os métodos convencionais. 
A secagem promove a remoção do líquido agregado e a redução do volume do alimento, facilitando assim o seu transporte. A secagem também é capaz de promover uma maior conservação microbiológica, além da concentração de compostos bioativos e antioxidantes. Um importante composto bioativo é o ácido ascórbico, comumente denominado por vitamina C, cuja função principal é a hidroxilação do colágeno (Basu et al., 2006), além de agir como um poderoso antioxidante capaz de transformar diversos radicais livres em formas inertes. $\mathrm{Na}$ presença de temperaturas elevas o composto sofre oxidação irreversível, perdendo a atividade biológica.

Um critério importante na avaliação da conservação de produtos alimentícios é a acidez. Além de controlar o número de microrganismos, a acidez total titulável compreende um conjunto de ácidos orgânicos, principalmente o ácido cítrico, que influenciam na coloração, textura e aroma dos alimentos. A presença de tais compostos é fundamental para uma boa qualidade da fruta (Souza et al., 2010).

Sendo assim, o objetivo deste trabalho foi analisar a cinética de secagem da physalis em função da temperatura, e determinar o comportamento dos compostos bioativos antes e depois do processo de desidratação.

\section{MATERIAIS E MÉTODOS}

\subsection{Materiais}

A Physalis peruviana Linnaeus utilizada neste trabalho foi obtida em uma mercearia localizada no Mercado Municipal de Uberaba. Posteriormente, as frutas foram conservadas em temperatura ambiente até o instante da sua utilização.

\subsection{Equipamentos e condições de secagem}

O estudo da secagem da physalis foi realizado em um equipamento analisador de umidade com o provimento de calor através da luz infravermelha. A variável manipulada foi a temperatura de secagem $\left(60^{\circ}, 70^{\circ}\right.$ e $\left.80^{\circ}\right)$, e o experimento foi realizado até que a umidade de equilíbrio fosse atingida.

As amostras foram pesadas e o equipamento foi pré-aquecido. A temperatura desejada foi então ajustada e a secagem iniciada. Dados de tempo e porcentagem de água extraída puderam ser vistos no visor digital do aparelho. O processo de desidratação se manteve até que uma diferença de $0,1 \%$ de umidade pudesse ser constantemente observada. Com posse de tais dados, foi possível o cálculo da razão de umidade (RU), segundo a Equação 1:

$$
R U=\frac{U_{(t)}-U_{e}}{U_{0}-U_{e}}
$$




\subsection{Análises físico-químicas}

Sólidos Solúveis Totais (SST): o teste foi realizado a partir de aproximadamente três gotas de suco de frutas, e indicado com o auxílio de um refratômetro manual. Os resultados foram expressos em ${ }^{\circ}$ Brix.

Teor de Vitamina C: examinada em $10 \mathrm{ml}$ de suco, acumulado em um erlenmeyer contendo $50 \mathrm{ml}$ de ácido oxálico a $1 \%(\mathrm{~m} / \mathrm{v})$. A titulação foi feita com o uso de 2,6diclorofenol-infofenol (DCFI) até a solução atingir um aspecto rosado persistente por 15 segundos. Os resultados foram retratados em mg de ácido ascórbico por $100 \mathrm{ml}$ de suco de frutas.

Acidez Total Titulável (ATT): promovida parcialmente segundo a metodologia utilizada por Giacobbo et al. (2008), que consiste na titulação potenciométrica de $10 \mathrm{ml}$ de suco com uma solução padrão de $\mathrm{NaOH}$ 0,1 $\mathrm{M}$ até atingir o $\mathrm{pH}$ de referência 8,2.

\subsection{Tratamento Estatístico}

A Tabela 1 apresenta os modelos de cinética de secagem que foram ajustados aos dados experimentais.

Tabela 1 - Modelos de cinética de secagem (Gardusi et al., 2014)

\begin{tabular}{cc}
\hline Equação & Modelo \\
\hline$R U=\exp (-k t)$ & Lewis \\
$R U=A \exp (-k t)$ & Brooker e colaboradores \\
$R U=A\left(\exp (-k t)+\frac{1}{9} \exp (-9 k t)\right)$ & Henderson e Henderson \\
$R U=\exp \left(-k t^{n}\right)$ & Page \\
\hline
\end{tabular}

A seleção do melhor modelo foi feita com base na magnitude do coeficiente de determinação $\left(R^{2}\right)$, bem como na significância dos parâmetros e na distribuição dos resíduos.

\section{RESULTADOS E DISCUSSÕES}

\subsection{Cinética de Secagem}

A Figura 1 mostra o comportamento das curvas do adimensional de umidade em função do tempo de secagem, em minutos, para cada uma das três temperaturas utilizadas, juntamente com a predição do modelo de Page, o qual estatisticamente foi o modelo que melhor descreveu a cinética de secagem da physalis. $\mathrm{O}$ valor do coeficiente de determinação médio foi de 0,9992 . 
Figura 1 - Cinética de secagem nas temperaturas de 60,70 e $80^{\circ} \mathrm{C}$ e o modelo de Page ajustado.

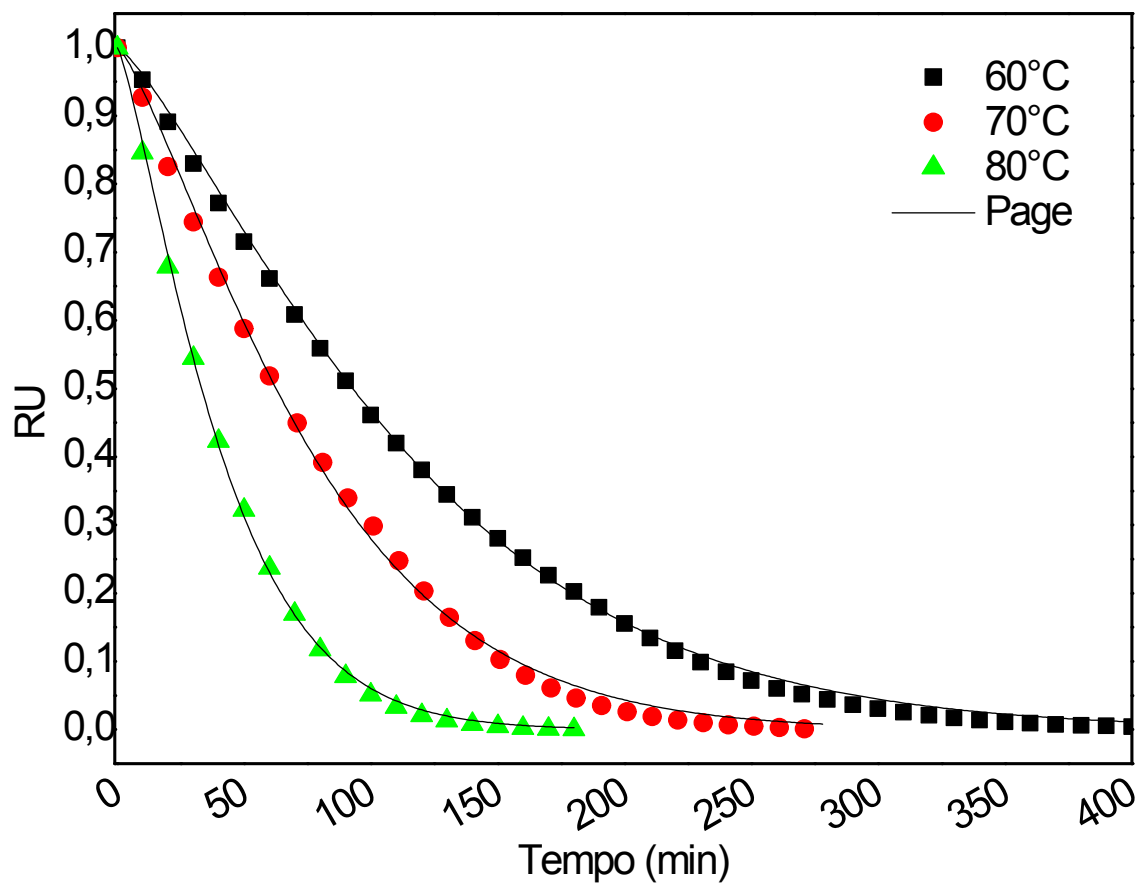

O tempo de secagem é dependente da temperatura de operação do infravermelho. Quanto maior essa temperatura, menor é o tempo necessário para que a umidade de equilíbrio seja atingida.

$\mathrm{Na}$ Tabela 2 são apresentados os parâmetros para esse modelo, assim como o coeficiente de determinação.

Tabela 2 - Parâmetros para o modelo de Page e coeficiente de determinação

\begin{tabular}{cccc}
\hline Experimento & $\mathbf{k}$ & $\mathbf{n}$ & $R^{2}$ \\
\hline $\mathbf{6 0}^{\circ} \mathbf{C}$ & 0,0021 & 1,2809 & 0,9995 \\
$\mathbf{7 0}^{\circ} \mathbf{C}$ & 0,0032 & 1,3020 & 0,9985 \\
$\mathbf{8 0}^{\circ} \mathbf{C}$ & 0,0081 & 1,2717 & 0,9996 \\
\hline
\end{tabular}

Azoubel et al. (2010) também encontraram o modelo de Page como sendo o que melhor retrata a cinética de secagem da manga. $\mathrm{O}$ experimento em questão foi realizado com e sem tratamento ultrassônico.

\subsection{Análises físico-químicas}

A Tabela 3 mostra o comportamento dos compostos bioativos da physalis antes e depois do processo de secagem. $\mathrm{O}$ teor de vitamina $\mathrm{C}$ foi analisado através da quantidade de ácido ascórbico (em $\mathrm{mg}$ ) existente em $100 \mathrm{~g}$ de fruta. No caso da acidez total, a análise foi feita com base no teor de ácido cítrico (em $\mathrm{mg}$ ) presente em $100 \mathrm{~g}$ de fruta. A temperatura de secagem e o tempo de operação do processo podem afetar a atividade dos compostos 
bioativos presentes na fruta. Assim, neste trabalho, foi avaliado o efeito que a temperatura de secagem exerce no teor de sólidos solúveis totais, vitamina $\mathrm{C}$ e acidez total titulável nas amostras submetidas ou não ao processo térmico.

Tabela 3 - Propriedades físico-químicas

\begin{tabular}{lccc}
\hline & $\begin{array}{c}\text { Sólidos solúveis } \\
\text { totais ( }\end{array}$ & $\begin{array}{c}\text { Teor } \mathbf{B r i x}) \\
(\mathbf{m g} / \mathbf{1 0 0} \mathbf{g})\end{array}$ & $\begin{array}{c}\text { Acidez total titulável } \\
(\mathbf{m g} / \mathbf{1 0 0} \mathbf{g})\end{array}$ \\
\hline in natura & 2,5 & 92,5 & 487,8 \\
\hline $\mathbf{6 0}^{\circ} \mathbf{C}$ & 10 & 233,2 & 1467 \\
\hline $\mathbf{7 0}^{\circ} \mathbf{C}$ & 8 & 195,7 & 2447 \\
\hline $\mathbf{8 0}^{\circ} \mathbf{C}$ & 7 & 132 & 2006 \\
\hline
\end{tabular}

O menor valor observado para a quantidade de sólidos solúveis totais, $2,5^{\circ} \mathrm{Brix}$ foi para a fruta in natura, enquanto que as diferentes amostras de material seco obtiveram valores de 10,8 e $7^{\circ}$ Brix, a 60,70 e $80^{\circ} \mathrm{C}$, respectivamente. Um aumento da temperatura de secagem fez com que a quantidade de ${ }^{\circ}$ Brix (sacarose) diminuísse, e mesmo assim os valores encontrados foram superiores aos da fruta in natura. O processo de secagem proporcionou melhora significativa no que tange a qualidade da fruta, visto que o índice de sacarose se mostra como um confiável indicativo da mesma.

O teor de ácido ascórbico encontrado no material úmido (in natura) apresentou-se como o menor valor, $92,5 \mathrm{mg}$ de ácido ascórbico em cada $100 \mathrm{~g}$ de fruta. Assim como a quantidade de sólidos solúveis, o teor de vitamina $\mathrm{C}$ foi superior nas amostras secas, mesmo que o valor se mostre decrescente com a temperatura. Dorta et al (2012) explica que o aumento do teor de ácido ascórbico após a secagem se deve à inativação de algumas enzimas capazes de degradar compostos bioativos.

O maior teor de acidez total titulável para a physalis foi após a secagem a $70^{\circ} \mathrm{C}$ ( $2447 \mathrm{mg}$ de ácido cítrico/100 g de fruta), enquanto que para a fruta in natura o valor encontrado foi expressamente inferior (487,8 mg de ácido cítrico/100 $\mathrm{g}$ de fruta).

\section{CONCLUSÃO}

A cinética de secagem por irradiação infravermelha foi um método eficiente e de simples realização para as condições utilizadas neste trabalho. A análise estatística dos dados experimentais relacionadas ao adimensional de unidade apontou o modelo de Page como o que melhor prediz os dados laboratoriais.

Uma análise das curvas que relaciona o adimensional de umidade com o tempo, mostrou que a duração do processo é dependente da temperatura de operação, a qual também pode interferir nos teores dos compostos bioativos e na possível desnaturalização dos mesmos. O índice de Grau Brix, assim como os teores de ácido ascórbico e cítrico apresentaram valores superiores quando analisados no material seco e comparados com os da fruta in natura. 


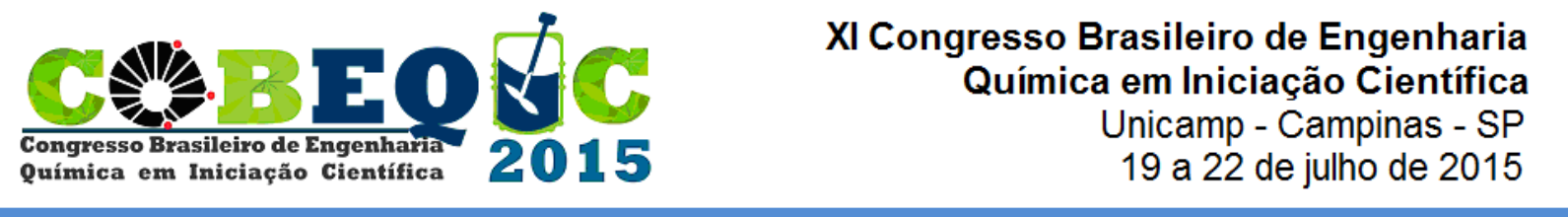

\section{NOMENCLATURA}

$R U$ razão de umidade (adimensional)

$U_{(t)}$ variação da umidade real com o tempo

$U_{e}$ umidade de equilíbrio

$U_{0}$ umidade inicial (obtida na estufa)

\section{REFERÊNCIAS}

AZOUBEL, P. M; AMORIM, M. R; OLIVEIRA, S. S. B; BAIMA, M. A. M; CASTRO, M. S. Cinética de secagem de manga com e sem pré-tratamento ultrassônico, 2010.

BASU, T. K.; DICKERSON, J.W. Vitamins in Human Health and Disease. $C A B$ International, 2006.

DORTA, E; LOBO, M. G; González, M. Using drying treatments to stabilise mango peel and seed: Effect on antioxidant activity. LWT-Food Science and Technology, 2012.

GARDUSI, F.; MENDES, L. G.; NOGUEIRA, G. D. R; SILVA, D. I. S.; BARROZO, M. A. S. Secagem da casca da mexerica por irradiação infravermelha e comparação dos compostos bioativos desta in natura e após a secagem, 2014.

GIACOBBO, C. L; ZANUZO, M; CHIM, J; FACHINELLO, J. C. Avaliação do teor de vitamina $\mathrm{C}$ em diferentes grupos de araçá-comum, 2008.

LUCHESE, C. L; Avaliação da influência da temperatura e da concentração da solução de sacarose na desidratação osmótica de physalis. Dissertação de mestrado, DEQ/UFRGS, 2013.

PUENTE, L. A; PINTO-MUÑOZ, C. A.; CASTRO, E. S.; CORTÉS, M. Physalis peruvianna Linnaeus, the multiple properties of a highly functional fruit: A review. Food Research International, v. 44, p. 1733-1740, 2011.

RAMADAN, M. F.; MOERSEL, J. T. Goldenberry: A novel fruit source of fat solube bioactives. Informative novel Crop Production, v. 15 (2), p. 130-131, 2004.

RAMADAN, M. F. Bioactive phytochemicals, nutriotional value, and functional properties of Cape gooseberry (Physalis peruviana): An overview. Food Research International, v. 44, p. 1830-1836, 2011.

SOUZA, L.M.; CORREIA, K. C.; SANTOS, A. M. H.; BARRETO, L. P.; NETO, E. B., (2010). Comparação de metodologias de análise de $\mathrm{pH}$ e acidez titulável. Anais JUPEX UFRPE, Recife - PE 